\title{
Parental mental health and child development from six to thirty-six months in a birth cohort study in Taiwan
}

\author{
For-Wey Lung ${ }^{1-4}$, Tung-Liang Chiang ${ }^{5}$, \\ Shio-Jean Lin ${ }^{6}$ and Bih-Ching Shu,** \\ ${ }^{1}$ Department of Medicine, Kaohsiung Armed Forces \\ General Hospital, Kaohsiung, Taiwan \\ 2 Graduate Institute of Behavioral Sciences, Kaohsiung \\ Medical University, Kaohsiung, Taiwan \\ ${ }^{3}$ Department of Psychiatry, National Defense Medical \\ Center, Taipei, Taiwan \\ ${ }^{4}$ Calo Psychiatric Center, Pingtung County, Taiwan \\ ${ }^{5}$ Institute of Health Policy and Management, College of \\ Public Health, National Taiwan University, Taipei, \\ Taiwan \\ ${ }^{6}$ Department of Pediatrics, National Cheng Kung \\ University Medical School, Tainan, Taiwan \\ 7 Department of Nursing, Institute of Allied Health \\ Sciences, National Cheng Kung University, Tainan, \\ Taiwan
}

\begin{abstract}
This study investigated the reciprocity between parental mental health and the different stages of child development at 6, 18, and 36 months. As the pilot of a birth cohort study, this study comprised 2048 children and their parents who were randomly selected and invited to participate. The development of these children and the mental health of their parents were followed at 6,18 , and 36 months postpartum. Child development was assessed using the Taiwan Birth Cohort Study instrument, and parental health was assessed using the Taiwanese version of the 36-Item Short Form Health Survey. Complete responses for all three stages were received from 844 families. Our results showed that parental mental health had a direct effect on language and social development; however, this effect did not become significant until 36 months. The reciprocity between child development and parental mental health and proper intervention are vital.
\end{abstract}

\footnotetext{
${ }^{*}$ Corresponding author:

Dr. Bih-Ching Shu

Department of Nursing

Institute of Allied Health Sciences

National Cheng Kung University

No. 1 Da-Hsueh Rd.

Tainan 701

Taiwan

Tel.: +886 62353535 \# 5822

Fax: +886 6273750

E-mail: forweylung@gmail.com/shubih@mail.ncku.edu.tw
}

Keywords: Early development; infant; parental mental health; postpartum depression.

\section{Introduction}

The role of mothers in the development of children has been studied extensively. Since a proportion of mothers have postpartum depression [16], a number of studies investigated the effect that maternal depressive symptoms might have on children [15, 22, 33]. Kahn et al. [18] found that when the mother has a poorer mental health, the father's better mental health may decrease the negative consequences that the maternal poor mental health might have on the behavioral and emotional development of the child. Additionally, greater paternal involvement may reduce the effect of maternal depression [26], and have a positive impact on child development [36]. However, in addition to the mothers, a proportion of fathers has also reported depression after birth [13]. If both parents have poor mental health, the children might have more severe behavioral and emotional problems [18]. Therefore, when investigating the influence of maternal mental health on children, paternal mental health should also be explored, for it may influence the effect that maternal mental health might have on children.

Montague and Walker-Andrews [27] found that as early as 3.5 months, infants were able to differentiate their maternal expressions, but the paternal or of unfamiliar adults. Kochanska and Akasan [20] similarly found that at seven months, infants were able to react to the socialinteractive, mood regulation and influencing attempts of both parents. This research shows that very early in infanthood, parent-child relationship patterns already have an effect on young children.

Many studies reported on the effect of mental symptoms on the way parents interact with their children [29, 30], but few studies investigated the persistent effect of parental health on children at such a young age, and even fewer studies investigated the effect of paternal mental health on children in the first few years of life [13, 19]. Cabrera and colleagues [5] reported that the sociocultural context in which children develop in the $21^{\text {st }}$ century differs from that of their parents. Now, a higher percentage of mothers enter the work force [39], leading to increased paternal involvement in parenting. Therefore, a need exists to consider the fathers, mothers and family structure in the investigation of child development [5]. Besides the effect of parental mental health on child 
development, children of low birth weight are more likely to have slower motor development [6], which affects maternal psychological distress until the age of two, and these parents still have increased parenting stress than do mothers to term babies at the age of three [32]. In the same line, parents of autism spectrum disorders [8] and other chronic illness [28] also experience higher parenting stress than others. Therefore, besides the effect of parental mental health on child development, the child's own development might, in turn, affect parental mental health.

In addition to parental mental health, parental level of education also has a significant effect on child development [24]. In addition to parental mental health and level of education, characteristics of birth weight and gestational age might also affect later child development. A previous study found that birth weight affects child's growth until age nine [4]. Other studies found that low birth weight and shorter gestations were associated with delayed motor development [6]. Therefore, in this study, parental level of education, birthweight and gestational age are included in our analysis as adjusted variables to exclude possible moderating effects on parental mental health and child development.

Using structural equation modeling, three different models were tested. The first model constructed the effect of parental health at six months on child development at 6,18 , and 36 months, and the non-recursive effect of children development affecting parental mental health (Figure 1A). The second model constructed the effect of parental health at 18 months on child development at 18 and 36 months, and the non-recursive effect of children development affecting parental mental health (Figure 1B). The third model constructed the effect of parental health at 36 months on the child development at 36 months, and the non-recursive effect of child development affecting parental mental health (Figure 1C). All dotted lines represent possible significant pathways. The aim of this study was to investigate the influence of different stages of paternal and maternal health on the development of children, as well as the non-recursive effect of child development on parental mental health, and difference between these effects at 6,18 , and 36 months.

\section{Patients and methods}

The protocol of this study was approved by the institutional review board of a teaching hospital. All children born between October 2003 and January 2004 in the Taichung area (Taiwan) were qualified to participate in this study. Of the 21,535 newborns in the 29 villages or cities in this area, 2048 were randomly selected, and they and their parents were invited to participate in this birth cohort pilot study. These children and their families were followed at three stages: when the children were 6,18 , and
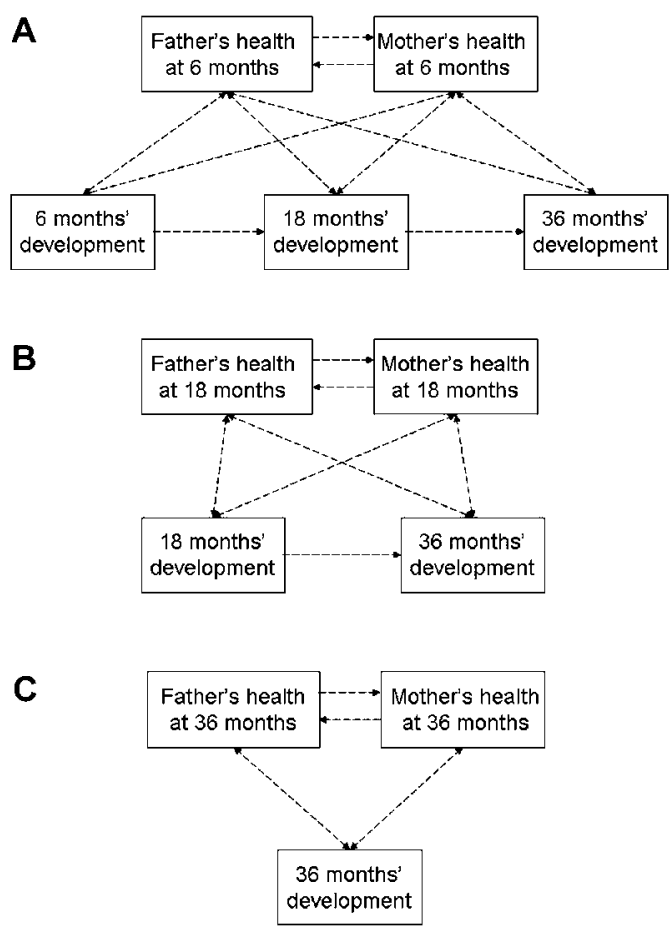

Figure 1 The hypothesized model of the relationship of parental health and children's development at 6, 18 and 36 months (dotted lines represent possible pathways).

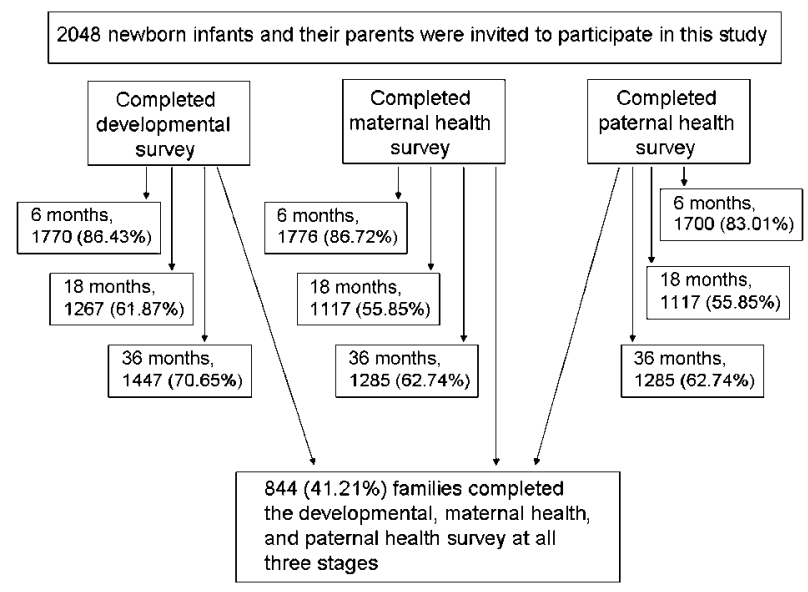

Figure 2 Overview of the participation rate at three different stages.

36 months old. The participation rate is shown in Figure 2: 844 (41.21\%) out of the 2048 families completed all three surveys at all three stages. All parents gave their informed consent for this study.

The parents were contacted at the three stages and if the parents agreed to participate in the study at the particular stage, the research assistant would visit the family at their home. The parents were asked to fill out a demographic information sheet, the Taiwan Birth Cohort Study (TBCS) developmental instrument, and each parent had to complete a Taiwanese version of the 36-Item Short Form Health Survey (SF-36).

The TBCS developmental instrument is a cultural-sensitive, comprehensive, short instrument assessing the development of 
children at 6, 18, and 36 months in Taiwan. It is a parent-report instrument measuring child development in the four domains of gross motor, fine motor, language and social development. The TBCS has good reliability and validity [23].

Parental health status was assessed using the Taiwanese version of the SF-36 [17]; this inventory includes 36 questions measuring the overall physical and mental health of an individual. The Taiwanese version was translated from the American version of the SF-36 developed by Ware and colleagues [40]; this instrument has a high reliability and validity in both the USA and Taiwan [7, 11, 38]. Although the SF-36 yields mental and physical health scores, mental health was the only area of interest in this study, so the physical health scores were not included in the analysis.

The demographic distribution of the families was analyzed using descriptive analysis in SPSS version 15.0 for Windows (Chicago, IL). Since only $41.21 \%$ of the participants completed all three measures in this study, comparisons between the followed-up and dropped-out family distribution were analyzed to ensure that our sample represented the larger randomly selected sample. The relationship between parental mental health and children characteristics at 6,18 , and 36 months were investigated using structural equation modeling. Structural equation modeling used the $\chi^{2}$-test to analyze the overall fit of the model. Models resulting in $\mathrm{P}>0.05$, and goodness-of-fit $>0.9$ indicate that the model adequately describes the observed data. Structural equation analysis was processed using AMOS 7.0 (SPSS) Figure 3.

\section{Results}

The demographic distributions of the followed-up and dropped-out families are shown in Table 1. The comparisons showed statistically significant differences between parental marital status $(P=0.003)$, with a higher proportion of non-married but cohabiting parents in the dropped-out group. Additionally, there were differences in maternal levels of education, with those willing to follow-up being of higher education $(P=0.053)$. There were 446 males $(52.8 \%)$ in the study group. Average maternal and paternal ages were 27.76 and 31.89 years, respectively.

The effect of parental mental health at six months adjusted for parental level of education, birth weight and gestational age on child development at 6,18 , and 36 months is shown in Figure 1A. The model resulted in a P-value of 0.126 and adjusted goodness-of-fit of 0.974 . The results suggest that mothers of children with better gross motor and language development at six months had better mental health at six months (gross motor: $P=0.005$; language: $P=0.018$ ), and mothers with better mental health had children with better social development at 36 months $(P=0.006)$. Conversely, children of fathers with better mental health had better language development at 36 months $(P=0.048)$.

The effect of parental mental health at 18 months adjusted for parental level of education, birth weight and gestational age on child development at 18 and 36 months is shown in Figure 1B. The model resulted in
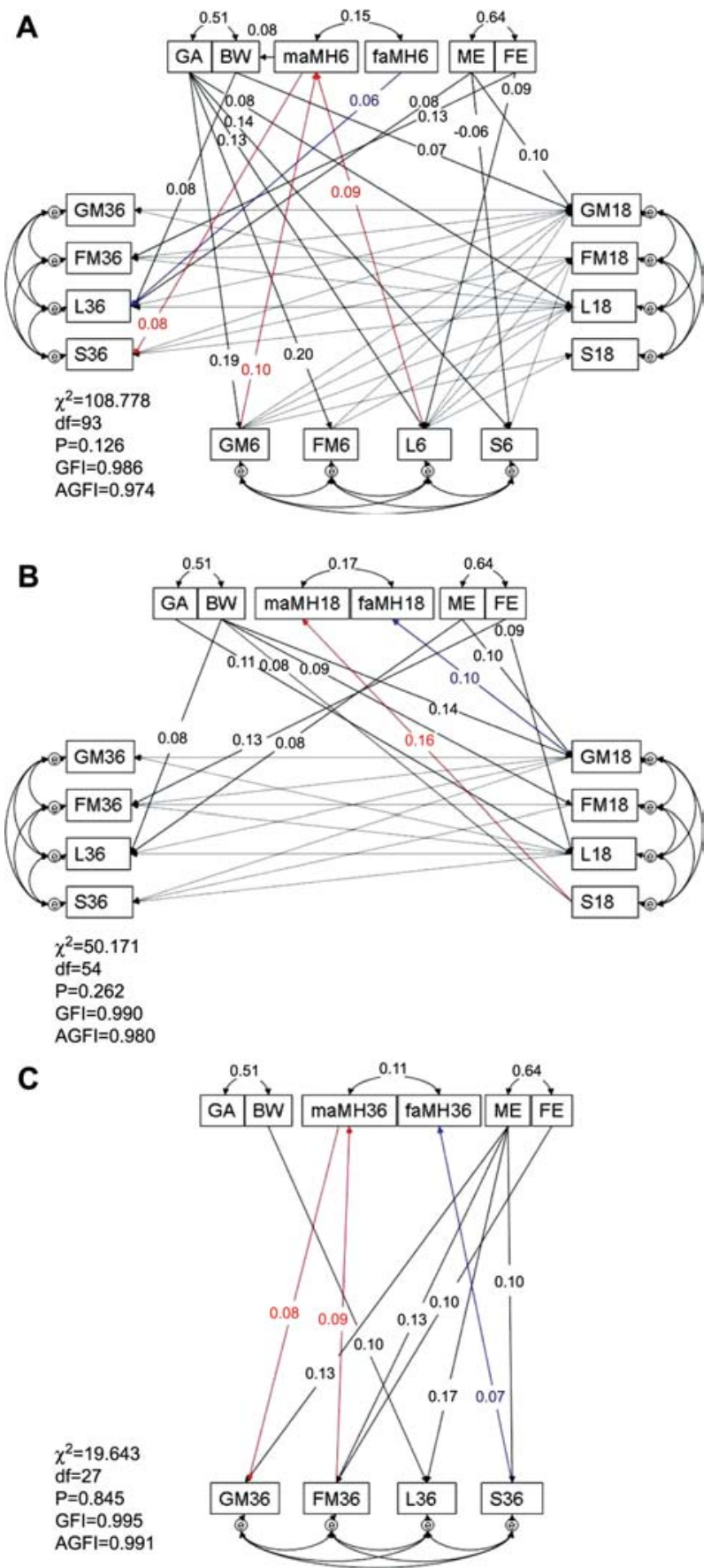

Figure 3 Structural equation modeling of the effect of parental health on child development at $6(\mathrm{~A}), 18(\mathrm{~B})$ and 36 months $(\mathrm{C})$. $\mathrm{GA}=$ gestational age, $\mathrm{BW}=$ birth weight, $\mathrm{MH}=$ mental health status, $\mathrm{ME}=$ maternal educational level, $\mathrm{FE}=$ paternal educational level, $\mathrm{GM}=$ gross motor development, $\mathrm{FM}=$ fine motor development, $\mathrm{L}=$ language development, $\mathrm{S}=$ social development, $\mathrm{GFI}=$ goodness-of-fit index, AGFI=adjusted goodness-of-fit index.

a P-value of 0.262 and adjusted goodness-of-fit of 0.980 . The results suggest that mothers of children with better social development at 18 months had better mental health $(P<0.001)$. Additionally, fathers of children with 
Table 1 Demographic distribution comparisons of parents between the drop-outs and the followed-up children and parents.

\begin{tabular}{|c|c|c|c|}
\hline & $\begin{array}{l}\text { Followed-up } \\
n=844\end{array}$ & $\begin{array}{l}\text { Dropped-out } \\
n=1199\end{array}$ & P-value \\
\hline & Mean (SD) & Mean (SD) & \\
\hline Maternal age (range 14-44) & $27.96(4.68)$ & $27.90(5.19)$ & 0.780 \\
\hline \multirow[t]{2}{*}{ Paternal age (range 16-54) } & $31.89(5.17)$ & $31.94(5.74)$ & 0.635 \\
\hline & $\mathrm{n}(\%)$ & n (\%) & \\
\hline Male & $446(52.8)$ & $671(52.8)$ & 0.176 \\
\hline \multicolumn{4}{|l|}{ Maternal level of education } \\
\hline High school or less & $479(56.8)$ & $573(61.3)$ & 0.053 \\
\hline College/university or higher & $365(43.2)$ & $361(38.7)$ & \\
\hline Missing & $0(0.0)$ & $267(13.1)$ & \\
\hline \multicolumn{4}{|l|}{ Paternal level of education } \\
\hline High school or less & $471(55.9)$ & $535(58.4)$ & 0.311 \\
\hline College/university or higher & $371(44.1)$ & 381 (41.6) & \\
\hline Missing & $2(0.2)$ & $285(23.77)$ & \\
\hline \multicolumn{4}{|l|}{ Parental marital status } \\
\hline Married and cohabiting & $825(97.7)$ & $891(95.1)$ & 0.003 \\
\hline Others & $19(2.3)$ & $46(4.9)$ & \\
\hline Missing & $0(0.0)$ & $264(12.9)$ & \\
\hline
\end{tabular}

better gross motor development at 18 months had better mental health $(P=0.005)$.

Figure $1 \mathrm{C}$ shows the effect of parental health at 36 months adjusted for parental level of education, birth weight and gestational age on child development at 36 months. The structural equation model resulted in a P-value of 0.845 and goodness-of-fit of 0.991 . Mothers of children with better fine motor development at 36 months had better mental health $(P=0.054)$, in turn, mothers with better mental health had children with better gross motor development $(P=0.003)$. On the other hand, fathers of children with better social development had better mental health $(P=0.038)$.

All three Figures show that child development at the current stage is predictive of later stages; Figure $1 \mathrm{~A}$ shows that child development at six months is predictive of development at 18 months, which, in turn, predicts the child's development at 36 months. Furthermore, maternal and paternal physical and mental health are significantly correlated.

\section{Discussion}

Our results suggest that parental mental health had a direct effect on child development; however, this effect is not significant until the children are 36 months old. On the other hand, at 6 months, child development affected maternal mental health and this effect expended to the mental health of both parents at 18 and 36 months.

The difference in the dimensions of child development and parental mental health can be interpreted as differences of attention of parents at the different stages of development since parenting practices are expressions of parental beliefs which is vital in child developmental niches [35]. During infanthood, mothers are generally the main caregiver, and fathers are more involved in social interaction [1], thus our study found that at 6 months, maternal mental health were more affected by child development, but this effect was not evident in fathers. Nevertheless, paternal involvement in care giving generally increases over time [1], thus our study found that at 18 and 36 months, the mental health of both parents were affected by child development. Our results suggest that until 36 months, fathers paid more attention to gross motor and social development but not to other dimensions, which is consistent with previous observations that fathers typically dedicate more time to socially interact with their children [1, 21].

At all three stages of six our results showed that maternal and paternal mental health was significantly correlated. This is consistent with previous observation which found that depression in one partner correlates with depression in the other [2, 31, 34]. Additionally, the impact of parental mental health on the development of 6-month-old children implies that at six months, children are possibly aware of their parents' emotional changes. Montague and Walker-Andrews [27] found that at 3.5 months, children were capable of differentiating their mother's, but not their father's expressions. Psychoanalytical investigators proposed that the beginnings of the separation-individuation phase between mother and child is at the age of about five or six months [14, 25].

Although in our study parental mental health at six months did have an effect on child development, this effect was not evident until children were 36 months old. At six months, maternal mental health affected children's social development at 36 months, and paternal mental health affected children's language development at 36 months. In Thomasgard and Metz model of the stages 
of emotional development [37], children learn the expression of emotion through modeling these behaviors from others in their environment that use these words to express emotions, thus showing that language is closely linked with the child ability to express emotion [37]. However, our results further show that, at 36 months, when children are older and more sensitive to their parents' emotions, maternal mental health had an instant and direct effect on child gross motor development. This is in line with previous studies suggesting that when children fail in attempting to express their emotions in words, they will express them by action [37]. Therefore, children of mothers with mental health symptoms are at a higher risk of having behavioral and emotional problems [18].

A limitation of our study is that all measurements were from self-report instruments. However, previous studies have shown that parental reports on the concerns of their children are highly reflective of true problems [10, 12]. In addition, parents who are depressed may have a bias in reporting their child development; however, a previous study showed that even though there is a bias of depressed mothers in reporting their children condition, there is still an association between maternal depression and child behavior [3]. The second limitation is the high drop-out rate in this study. This is a critical issue in a randomized urban longitudinal study, since the parents feel no obligation to provide us with such information. There is however, a difference in parental marital status and maternal level of education between the two groups, thus our results might be more suitable for middle class married and cohabiting families. The third limitation is that although we tried to adjust for parental level of education and characteristics of birth weight and gestational age, there are many other factors which may effect child development. Additionally, precipitating factors may mediate between parental mental health and child development. Thus the direct effect of parental mental health on child development will be reduced and these precipitating factors will show stronger effects. However, these data and results still provide useful information regarding the interaction between parental health and child development.

Increasing attention has been focused on the effect of parents with postpartum depressive symptoms [13, 16] on their children $[18,30]$. There is a high risk of couple morbidity in postpartum depression [9]. Our study showed that additionally, until 36 months, children own development has a non-recursive and vital effect on parental mental health. Thus the recognition of postpartum parental mental health and the reciprocity between child development and parental mental health are vital. Clinicians should be aware of parents of children with developmental delay and follow the effect the developmental status on parenting stress. Intervention should be provided to these parents to alleviate their mental health condition when necessary.

\section{Acknowledgements}

This study was supported by a grant from the Bureau of Health Promotion (DOH93-HP-1702). The views expressed herein are the authors' own. The study has relied on the work of many colleagues. We also thank the families who gave us such generous cooperation at all stages of the study.

\section{References}

[1] Bailey WT. A longitudinal study of fathers' involvement with young children: infancy to age 5 years. J Genet Psychol. 2004;155:331-9.

[2] Ballard CG, Davis PC, Cullen PC, Mohan RN, Dean C. Prevalence of psychiatric morbidity in mothers and fathers. Br J Psychiatry. 1994;164:782-8.

[3] Boyle MH, Pickles AR. Influence of maternal depressive symptoms on ratings of childhood behavior. J Abnorm Child Psychol. 1997;25:399-412.

[4] Buckler JM, Green M. The growth of twins between the ages of 2 and 9 years. Ann Hum Biol. 2008;35:75-92.

[5] Cabrera NJ, Tamis-LeMonda CS, Bradley RH, Hofferth S, Lamb ME. Fatherhood in the twenty-first century. Child Dev. 2000;71:127-36.

[6] Cheung YB, Yip PSF, Karlberg JPE. Fetal growth, early postnatal growth and motor development in Pakistani infants. Int J Epidemiol. 2001;30:66-74.

[7] Chie WC, Huang CS, Chen JH, Cheng KJ. Measurement of the quality of life during different clinical phases of breast cancer. J Formos Med Assoc. 1999;98:254-60.

[8] Davis NO, Carter AS. Parenting stress in mothers and fathers of toddlers with autism spectrum disorders: associations with child characteristics. J Autism Dev Disord. 2008;38:1278-92.

[9] Edhborg M, Matthiesen AS, Lundh W, Widstrom AM. Some early indicators for depressive symptoms and bonding 2 months postpartum - a study of new mothers and fathers. Arch Womens Ment Health. 2005;8:221-31.

[10] Filipek PA, Accardo PJ, Ashwal S, Baranek GT, Cook EH Jr, Dawson G, et al. Practice parameter: screening and diagnosis of autism: report of the Quality Standards Subcommittee of the American Academy of Neurology and the Child Neurology Society. Neurology. 2000;55:468-79.

[11] Fuh JL, Wang SJ, Lu SR, Juang KD, Lee SJ. Psychometric evaluation of a Chinese (Taiwanese) version of the SF-36 health survey amongst middle-aged women from a rural community. Qual Life Res. 2000;9:675-83.

[12] Glascoe FP, Foster EM, Wolraich ML. An economic analysis of developmental detection methods. Pediatrics. 1997; 99:830-7.

[13] Goodman JH. Paternal postpartum depression, its relationship to maternal postpartum depression, and implications for family health. J Adv Nurs. 2004;45:26-35.

[14] Hamilton NG. Self and others: object relations theory in practice. London, England: Jason Aronson; 1998.

[15] Hipwell AE, Goossens FA, Melhuish EC, Kumar R. Severe maternal psychopathology and infant-mother attachment. Dev Psychopathol. 2000;12:157-75.

[16] Josefsson A, Berg G, Nordin C, Sydsjo G. Prevalence of depressive symptoms in late pregnancy and postpartum. Acta Obstet Gynel Scand. 2001;80:251-5.

[17] Ju JFR, Tseng HM, Tsai YJ. Assessment of health-related quality of life in Taiwan (I): development and psychometric 
testing of SF-36 Taiwan version. Taiwan J Public Health. 2003;22:501-11.

[18] Kahn RS, Brandt D, Whitaker RC. Combined effect of mothers' and fathers' mental health symptoms on children's behavioral and emotional well-being. Arch Pediatr Adolesc Med. 2004;158:721-9.

[19] Kane P, Garber J. The relationship among depression in fathers, children's psychopathology, and father-child conflict: a meta-analysis. Clin Psychol Rev. 2004;45:26-35.

[20] Kochanska G, Akasan N. Development of mutual responsiveness between parents and their young children. Child Dev. 2004;75:1657-76.

[21] Lewis $M$, Feiring $C$, Weinraub $M$. The father as a member of the child's social network. In: Lamb ME, editors. The role of the father in child development. $2^{\text {nd }}$ ed. New York: Wiley; 1981, p. 259-94.

[22] Luoma L, Tamminen T, Kaukonen P, Laippala P, Puura K, Salmelin R, et al. Longitudinal study of maternal depressive symptoms and child well-being. J Am Acad Child Adolesc Psychiatry. 2001;40:1367-74.

[23] Lung FW, Shu BC, Chiang TL, Lin SJ. Efficient developmental screening instrument for 6- and 18-month-old children in the Taiwan Birth Cohort pilot Study. Acta Paediatr. 2008. Epub ahead of print.

[24] Lung FW, Shu BC, Chiang TL, Lin SJ. Parental mental health, education, age at childbirth and child development from six to 18 months. Acta Paediatr. in press.

[25] Mahler MS, Pine F, Bergman A. The psychological birth of the human infant. New York: Basic Books; 1975.

[26] Mezulis AH, Hyde JS, Clark R. Father involvement moderates the effect of maternal depression during a child's infancy and child behaviour problems in kindergarten. $J$ Fam Psychol. 2004;18:575-88.

[27] Montague DR, Walker-Andrews AS. Mothers, fathers, and infants: the role of person familiarity and parental involvement in infants' perception of emotional expressions. Child Dev. 2002;73:1339-52.

[28] Mussatto K. Adaptation of the child and family to life with a chronic illness. Cardiol Young. 2006;16:110-6.

[29] Ramchandani P, Stein A. The impact of parental psychiatric disorder in children. Br Med J. 2003;327:242-3.

[30] Ramchandani P, Stein A, Evans J, O'Connor TG. Paternal depression in the postnatal period and child development: a prospective population study. Lancet. 2005;265:22015.

[31] Ramchandani PG, Stein A, O'Connor TG, Heron J, Murray $\mathrm{L}$, Evans J. Depression in men in the postnatal period and later child psychopathology: a population cohort study. J Am Acad Child Adolesc Psychiatry. 2008;47:390-8.

[32] Singer LT, Salvator A, Guo S, Collin M, Lilien L, Baley J. Maternal psychological distress and parenting stress after the birth of a very low-birth-weight infant. J Am Med Assoc. 1999;281:799-812.

[33] Sohr-Preston SL, Scaramella LV. Implications of timing of maternal depressive symptoms for early cognitive and language development. Clin Child Fam Psychol Rev. 2006;9:65-83.

[34] Soliday E, McCluskey-Fawcett K, O’Brien M. Postpartum affect and depressive symptoms in mothers and fathers. Am J Orthopsychiatry. 1999;69:30-7.

[35] Super CM, Harkness S. The developmental niche. In: Lonner WJ, Malpass RS, editors. Psychology and Culture. Needham Heights, MA: Allyn and Bacon; 1994, p. 95-9.

[36] Tamis-LeMonda CS, Shannon JD, Cabrera NJ, Lamb ME. Fathers and mothers at play with their 2- and 3-year-old: contributions to language and cognitive development. Child Dev. 2004;75:1806-20.

[37] Thomasgard M, Metz WP. Promoting child social-emotional growth in primary care settings: using a developmental approach. Clin Pediatr. 2004;32:119-27.

[38] Tseng HM, Lu JF, Tsai YJ. Assessment of health-related quality of life in Taiwan (II): norming and validation of SF36 Taiwan version. Taiwan J Public Health. 2003;22:512-8.

[39] U.S. Census Bureau. Women in the labor force. U.S. USA: Department of Labor Editors; 2004.

[40] Ware JE Jr, Gandek B, Kosinski M, Aaronson NK, Apolone $\mathrm{G}$, Brazier J, et al. The equivalence of SF-36 summary health scores estimated using standard and country-specific algorithms in 10 countries: results from the IQOLA Project International Quality of Life Assessment. J Clin Epidemiol. 1998;51:1167-70.

The authors stated that there are no conflicts of interest regarding the publication of this article.

Received September 8, 2008. Revised December 25, 2008. Accepted January 26, 2009. Previously published online March 17, 2009. 